\title{
NOSOCOMIAL ROTAVIRAL GASTROENTERITIS IN PAEDIATRIC DEPARTMENTS
}

\author{
Mária Štefkovičová ${ }^{1}$, Pavol Šimurka ${ }^{2}$, Lenka Juračková ${ }^{2}$, Henrieta Hudečkováa ${ }^{3}$ Rastislav Mad'ar ${ }^{3}$ \\ ${ }^{1}$ Regional Office of Public Health in Trenčín, Slovak Republic \\ ${ }^{2}$ Teaching Hospital in Trenčín, Slovak Republic \\ ${ }^{3}$ Institute of Public Health, JLF UK Martin, Slovak Republic
}

\section{SUMMARY}

The authors present a retrospective analysis of community-acquired and hospital-acquired rotaviral gastroenteritis (RVGE) cases in a 5 years period 2001-2005 and prospective analysis in 2006 in the referral area in a population of 7,000 children under 5 years of age.

Out of 228 patients with RVGE, nosocomial RVGE accounted for $27.75 \%$ of the cases. Children with nosocomial RVGE were in average 9.8 months younger compared to patients with community-acquired RVGE. Nosocomial cases were also characterised by the need for longer stay in intensive care, overall longer hospital stay, longer duration of the illness and by lower age of the patients.

The wider implementation of vaccination in the youngest members of the population would be likely to have a significant influence on the occurrence of not only community-acquired but also hospital-acquired RVGE.

Key words: rotaviral gastroenteritis, hospital-acquired, community-acquired

Address for correspondence: M. Štefkovičová, Department of Epidemiology, Regional Office of Public Health, Nemocničná 4, 91101 Trenčín, Slovak Republic. E-mail: stefkovicova@gmail.com.

\section{INTRODUCTION}

Nosocomial infections present an important health, ethical, economical and also legal problems for health-care institutions. Their annual cost in European Union member countries amounts to between 15 and 24 billion EUR (8). In the USA there have been 2 million reported cases of hospital-acquired infections annually that had required an expenditure of 4.5 billion USD (5).

In dealing with infections the highest priority is usually given to those of bacterial origin. Surgical site, respiratory tract, catheterrelated, blood-stream and urinary tract infections are considered to be the most important ones in the nosocomial environment $(7,10)$. Viral infections are often only given secondary attention although some of them cause serious health impairment to specific groups of the population and may cause significant operational problems to health care institutions. One of these is rotaviral gastroenteritis (RVGE), which is the most common nosocomial infection in paediatric departments (3).

Children admitted to hospital suffering from RVGE present a potentially serious source of infection for other hospitalised children as they discharge massive viral loads of rotaviruses during the acute phase of illness. $1 \mathrm{ml}$ of faeces contains up to $10^{12}$ viral particles. The infectious dose that is sufficient to cause the illness is a mere 10 particles (9).

Amongst the important factors in the chain of transmission are the health-care workers (HCW). Rotaviruses were found on the hands of $76-78 \%$ of HCW taking care of children suffering from
RVGE $(1,4)$. Another important source of infection are children with asymptomatic infection. The proportion of these nosocomial rotaviral infections has been found to be between 18-39\% (1, 2, $4,6)$. The risk of obtaining an RVGE infection increases with the length of hospital stay (3).

Rotaviruses are similar to other non-capsulated viruses e.g. polioviruses and hepatitis A virus and are rather resistant to various physical and chemical factors. They are resistant to ether, fat solvents and a wide range of disinfection solutions. They are also relatively resistant to factors in the outside environment (9). This knowledge contributes to the facts stated in well known guides about intestinal nosocomial infections prevention that nosocomial RVGE occurs almost regularly in winter time in paediatric, infectious diseases, geriatric and psychiatric departments.

A high proportion of asymptomatic infections (20-40\%), high contagiousness, and a significant viral resistance to disinfection agents facilitate the infection spread at departments and decreases the likelihood of successful outcomes for infection control measures taken, e.g. hand hygiene, isolation of infected patients (3). In winter months, during the seasonal peak of RVGE, the infection overlaps with the occurrence of influenza infection and post-influenza complications. The nosocomial spread of RVGE may present a serious problem in the organisation and operational running in health care institutions and especially in the paediatric and infectious diseases departments leading to them claiming disproportionate costs. 


\section{MATERIAL AND METHODS}

Laboratory confirmed cases of RVGE hospitalised at the the Paediatric Department of the Teaching Hospital in Trenčín (TH) were analysed. The referral area of TH included 40,583 children up to 18 years of age, out of which 7,424 were under 5 years of age from the districts Trenčín and Nové Mesto nad Váhom. The following indicators were followed: the number of illnesses according to age groups, morbidity, the proportion of RVGE out of all gastroenteritis cases and out of all hospitalisations at the Paediatric Department, the proportion of community-acquired and hospital-acquired RVGE and the seriousness of the illness. The data are compared with reported cases recorded by the all country surveillance system EPIS (the Epidemiological Information System).

The seriousness of illness was derived from the length of treatment in the intensive care unit (ICU), the duration of hospital stay, the duration of fever, diarrhoea and vomiting (in days), the number of days of intravenous treatment, and the total length of the illness. The duration of hospital stay due to N-RVGE was calculated as a difference between the day of first symptoms and the date of discharge from the hospital.

The laboratory diagnosis of rotaviral infection was based on stool sample examination by ELISA Combi-strip diagnostic test (CorisBioconcept, Belgium). Only children with clinical symptoms of gastroenteritis were examined, asymptomatic forms of infection were not included.

\section{RESULTS}

In the followed period 2001-2006 altogether 228 cases of RVGE were recorded at the Paediatric Department of the selected Teaching Hospital in children under 5 years of age. The total number of all RVGE cases in children below 18 years of age was 267. The highest morbidity occurred in children under 1 year

Table 1. Age-specific morbidity in children with N-RVGE and C-RVGE

\begin{tabular}{|l|c|c|c|}
\hline \multirow{2}{*}{ Age group } & \multicolumn{3}{|c|}{ Average yearly morbidity/100,000 Children } \\
\cline { 2 - 4 } & N-RVGE & C-RVGE & RVGE total \\
\hline 0-12 months & 284.1 & 272.7 & 556.7 \\
\hline 1 years & 246.2 & 570.8 & 828.2 \\
\hline 2 years & 55.9 & 391.7 & 447.7 \\
\hline 3 years & 67.1 & 391.7 & 458.9 \\
\hline 4 years & 44.8 & 235.1 & 279.8 \\
\hline 5-9 years & 0 & 63.3 & 63.3 \\
\hline 10-14 years & 1.5 & 5.8 & 7.3 \\
\hline 15-19 years & 0 & 1.3 & 1.3 \\
\hline
\end{tabular}

RVGE - Rotaviral gastroenteritis

N-RVGE - Nosocomial rotaviral gastroenteritis

C-RVGE - Community rotaviral gastroenteritis

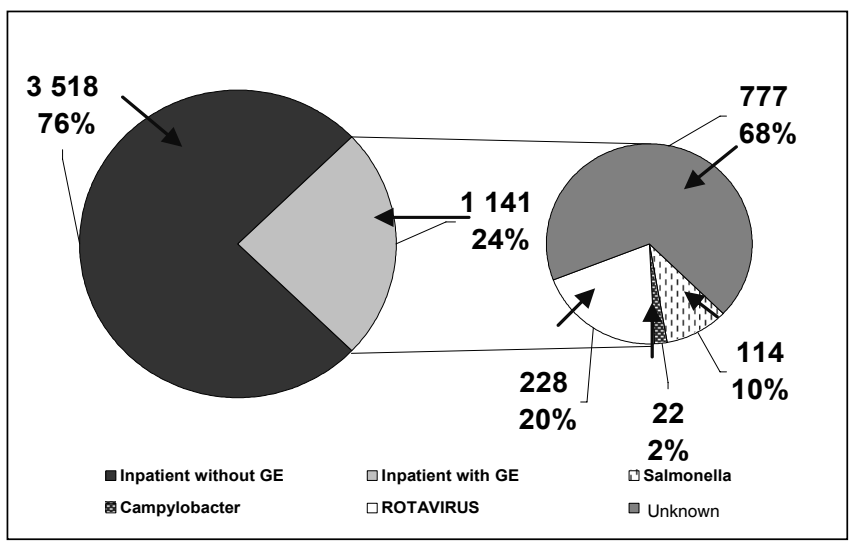

Fig. 1. Gastroenteritis cases (GE) in Trenčín region in hospitalised children according to aethiology, years 2001-2006, children up to 5 years.

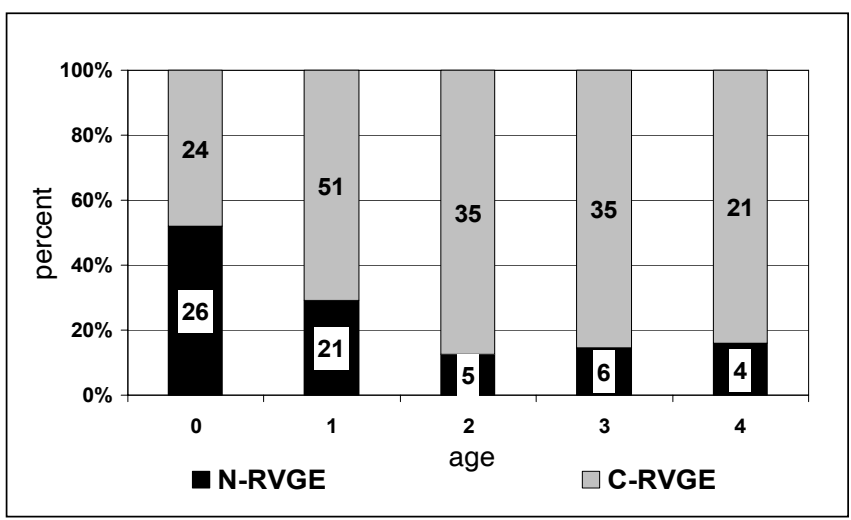

Fig. 2. Nosocomial and community RVGE according to age.

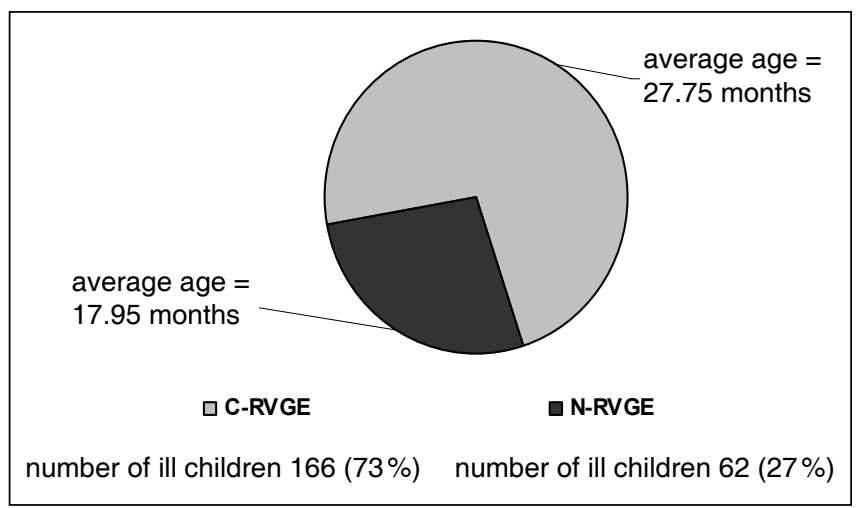

Fig. 3. The proportion of community and nosocomial RVGE, children up to 5 years of age.

of age (556.7/100,000), followed by the age group of children between 1 and 4 years of age $(500.8 / 100,000)$. The morbidity in older age categories was significantly lower (Table 1 ). The stated morbidity is referring to cases requiring hospital admission and does not describe the total morbidity in the region.

The total number of hospitalised gastroenteritis cases in the Paediatric Department in the 6-year study period was 1,635 - this figure represents $14.3 \%$ of all hospitalised children. In children un- 
Table 2. Seriousness of N-RVGE and C-RVGE in children below 5 years of age

\begin{tabular}{|c|c|c|c|c|}
\hline & \multicolumn{4}{|c|}{ RVGE in children below 5 years of age } \\
\hline & Total & C-RVGE & N-RVGE & $\mathrm{p}$ \\
\hline & \multicolumn{3}{|c|}{ The average in days } & \\
\hline Diarrhoea & 2.91 & 2.99 & 2.71 & 0.884 \\
\hline Vomiting & 1.86 & 1.89 & 1.79 & 0.736 \\
\hline Fever & 1.86 & 1.82 & 2.20 & 0.928 \\
\hline ICU stay & 0.82 & 0.75 & 1.03 & 0.124 \\
\hline Infusion therapy days & 2.11 & 2.38 & 1.79 & 0.942 \\
\hline Duration of hospital stay & 4.74 & 3.78 & 7.32 & $<0.001$ \\
\hline Duration of illness & 5.52 & 5.23 & 6.31 & 0.124 \\
\hline Average age (years) & 2.10 & 2.30 & 1.50 & $<0.001$ \\
\hline
\end{tabular}

RVGE - Rotaviral gastroenteritis

N-RVGE - Nosocomial rotaviral gastroenteritis

C-RVGE - Community rotaviral gastroenteritis

Table 3. Selected epidemiological characteristics of N-RVGE

\begin{tabular}{|l|c|c|}
\hline & \multicolumn{2}{|c|}{ Children } \\
\hline & below 18 years & below 5 years \\
\hline Number of children (districts Trenčín + Nové Mesto n. Váhom) & 40,583 & 4,424 \\
\hline Number of hospitalised children (years 2001-2006) & 9,717 & 166 \\
\hline Number of C-RVGE (years 2001-2006) & 204 & 62 \\
\hline Number of N-RVGE (years 2001-2006) & 63 & 1.33 \\
\hline Number of N-RVGE/number of all hospitalised children (in\%) & 0.65 & 139.2 \\
\hline Number of N-RVGE/100,000 children (annual average) & 25.9 & 0.37 \\
\hline Number of N-RVGE/number of C-RVGE & 0.31 & 3.25 \\
\hline Incidence of N-RVGE/1,000 bed-days (annual average) & 1.72 & 27.19 \\
\hline Proportion N-RVGE of all RVGE (in \%) & 23.59 & \\
\hline
\end{tabular}

RVGE - Rotaviral gastroenteritis

N-RVGE - Nosocomial rotaviral gastroenteritis

C-RVGE - Community rotaviral gastroenteritis

der 5 years of age the proportion of gastroenteritis cases was even higher at $24.5 \%$ (1,141 cases out of 4,659 hospitalised children). Rotaviruses were responsible for $20.0 \%$ of the gastroenteritis cases, followed by salmonellosis cases for $10.0 \%$ of cases, then campylobacteriosis $1.9 \%$, and adenoviral gastroenteritis occurring in $1.1 \%$ of cases. However, the causative agent of the majority (67.9\%) of all gastroenteritis cases in children under 5 years of age was not found (Fig. 1). Nosocomial RVGE (N-RVGE) comprised $23.6 \%$ of all cases and in children under 5 years of age the figure rose to $27.2 \%$. The figure in children under 1 year of age reached $53.8 \%$ and in children of 1 year of age $30.1 \%$. In higher age groups their occurrence significantly dropped (Fig. 2).
The average age of children hospitalised due to communityacquired RVGE was 27.75 months and due to nosocomial RVGE was 17.95 months (Fig. 3).

It was noted that children with nosocomial RVGE required longer stay at ICU, longer inpatient stay, and that they had a longer duration of illness (Table 2).

The diagnosis of nosocomial RVGE was established in 1.33 $\%$ of all hospitalised children under 5 years of age representing morbidity of 139.2/100,000 and an incidence of 3.25/1,000 beddays (Table 3).

Out of the total 62 children with N-RVGE, 18 children (29.0\%) presented with their first symptoms of nosocomial RVGE 
Table 4. Proportion of N-RVGE and other nosocomial infection in Slovakia and Trenčín region according to EPIS

\begin{tabular}{|c|c|c|c|c|c|c|}
\hline & \multicolumn{3}{|c|}{ SR } & \multicolumn{3}{|c|}{ Referral area of TN } \\
\hline & NI & N-RVGE & $\%$ & NI & N-RVGE & $\%$ \\
\hline 2001 & 302 & 20 & 6.6 & 9 & 3 & 30 \\
\hline 2002 & 316 & 23 & 7.3 & 21 & 7 & 30 \\
\hline 2003 & 343 & 22 & 6.5 & 23 & 5 & 21.7 \\
\hline 2004 & 338 & 30 & 8.9 & 5 & 0 & 0 \\
\hline 2005 & 232 & 45 & 19.4 & 11 & 4 & 36.4 \\
\hline 2006 & 290 & 72 & 24.8 & 26 & 16 & 61.5 \\
\hline TOTAL & 1,821 & 212 & 11.6 & 95 & 35 & 36.8 \\
\hline
\end{tabular}

N-RVGE - Nosocomial rotaviral gastroenteritis

$\mathrm{NI}$ - Nosocomial infection

SR - Slovakia

TN - Trenčín

EPIS - Epidemiological Information System

after their discharge from the hospital following treatment for another illness and they therefore required re-admission to treat the N-RVGE.

Based on the data recorded in EPIS database it was found out that nosocomial RVGE made up 36.8\% of all nosocomial infections reported in the Paediatric Department of the Teaching Hospital in Trenčín in period studied (Table 4). The proportion of nosocomial RVGE out of all nosocomial infections in all of Slovakia was only $11.6 \%$. It was also found that EPIS recorded only 35 cases of N-RVGE from Trenčín region while our analysis discovered in the Trenčín Teaching Hospital 62 cases in the same time.

\section{DISCUSSION}

Nosocomial RVGE presents a serious epidemiological and economical problem in many European countries. Nosocomial rotaviral infections were closely followed in six European countries (France, Germany, Italy, Poland, Spain and Great Britain). They make up 0.3 to $27.7 \%$ of all in-patient cases in children with the incidence $160-630 / 100,000$ in paediatric patients up to 5 years of age and 1.6-15.8 per 1,000 bed-days. It is estimated that there are 3,000 to 20,000 RVGE cases annually in children under 5 years of age in six European countries (3).

In our study group of children under 5 years of age hospitalised at the Paediatric Department the incidence of nosocomial RVGE was $139.2 / 100,000$. It was $27.2 \%$ of all RVGE requiring hospital admission and $1.33 \%$ of all hospitalised children. The average age of patients with nosocomial RVGE was lower by 9.8 months when compared to community-acquired cases. The highest occurrence of N-RVGE was in children from birth to 12 months of age $41.94 \%$ and in 1 year olds was $33.87 \%$.

European studies found prolongation of hospital stay due to nosocomial RVGE by 1.7-5.9 days and hospital re-admission due to nosocomial RVGE after the patient discharge (following treatment for other illnesses) at between $2-13 \%$ (3).
In our study group, the average length of hospital stay due to N-RVGE in children was 7.32 days compared to 3.78 days in community-acquired RVGE. The average duration of a hospital stay at the Paediatric Department was 4.0 days. It is hard to set in stone the real prolongation period of a hospital stay since the borderline between the need for hospitalization due to primary diagnosis and nosocomial retroviral infection is not exact. In our study group of 228 children, readmission due to RVGE occurring after discharge from hospital was recorded 18 times (7.9\% of all cases of RVGE and $29.0 \%$ of N-RVGE).

When comparing our data with country data recorded in EPIS (epidemiological information system) it is possible to assume that many health-care institutions likely do not report nosocomial infections even though this duty is mandatory. It is even more remarkably startling in RVGE cases as these have a tendency to be epidemic outbreaks.

The increased availability of vaccination to young children may have a significant effect on the decrease of community as well as nosocomial RVGE. However, currently, there are no sufficient data to establish the exact efficacy of an individual vaccination on the infection acquisition process and the transmission of nosocomial infections in hospitalised children.

\section{CONCLUSION}

Although N-RVGE presents an important epidemiological and economical problem in the majority of European countries, the available data on their incidence and seriousness are not sufficient and extrapolation of the data recorded in a limited area is problematic due to specific population anomolies. In addition to that, infection control by means of non-specific measures is difficult due to viral resistance, its renowned ability to survive on surfaces, inadequate spatial conditions in departments and ignorance or unfamiliarity with preventive and control measures.

Rotavirus is a major cause of acute gastroenteritis in young children worldwide. In developing and industrialized countries 
all children are infected with rotavirus during early childhood and rotavirus is the most common cause of diarrhoeal hospitalizations. It presents public health problem with societal perspective. Vaccination of a recently licensed rotavirus vaccine can effectively reduce the disease burden and healthcare costs.

\section{REFERENCES}

1. Suetens C, Savey A, Labeeuw J, Morales I; HELICS-ICU. The ICUHELICS programme: towards European surveillance of hospital-acquired infections in intensive care units. Euro Surveill. 2002 Sep;7(9):127-8.

2. Martone WJ, Jarvis WR, Culver DH, Haley RW. Incidence and nature of endemic and epidemic nosocomial infections. In: Bennett JV, Brachman PS, editors. Hospital infections. 3rd ed. Boston: Little, Brown, and Company; 1992. p. 577-96.

3. Suetens C. Healthcare associated infections in Europe: burden and surveillance study. In: Improving patient safety in Europe. Annual IPSE meeting; 2006 Nov 16-17; Vienna. Vienna: IPSE; 2006.

4. Wenzel RP, Brewer TF, Butzler JP. A guide to Infection Control in the Hospital. Boston: International Society for Infection Diseases; 2002.
5. Gleizes O, Desselberger U, Tatochenko V, Rodrigo C, Salman N, Mezner $Z$, et al. Nosocomial rotavirus infection in European countries: a review of the epidemiology, severity and economic burden of hospital-acquired rotavirus disease. Pediatr Infect Dis J. 2006 Jan;25(1 Suppl):S12-21.

6. Šrámková L, Rýc M. Virus gastroenteritides in clinical practice. Prague: Grada Avicenum; 1993. (In Czech.)

7. Cone R, Mohan K, Thouless M, Corey L. Nosocomial transmission of rotavirus infection. Pediatr Infect Dis J. 1988 Feb;7(2):103-9.

8. Gianino P, Mastretta E, Longo P, Laccisaglia A, Sartore M, Russo R, et al. Incidence of nosocomial rotavirus infections, symptomatic and asymptomatic, in breast-fed and non-breast-fed infants. J Hosp Infect. 2002 Jan;50(1):13-7.

9. Ferson MJ, Stringfellow S, McPhie K, McIver CJ, Simos A. Longitudinal study of rotavirus infection in child-care centres. J Paediatr Child Health. 1997 Apr;33(2):157-60.

10. Román Riechmann E, Wilhelmi de Cal I, Cilleruelo Pascual ML, Calvo Rey C, García García ML, Sánchez-Fauquier A. Nosocomial gastroenteritis and asymptomatic rotavirus and astrovirus infection in hospitalized children. An Pediatr (Barc). 2004 Apr;60(4):337-43. (In Spanish.)

Received September 29, 2007 Accepted in revised form November 20, 2007 